\title{
SURGICAL RELIEF OF SNORING BY THE TECHNIQUE OF PALATAL TIGHTENING: PRELIMINARY RESULTS
}

\author{
ME Baraka, Consultant; JY Osammor, Clinical Assistant; AA Kochhar, \\ Clinical Assistant; RJ Flockton, SHO; ENT Department, Royal Lancaster Infirmary
}

\section{INTRODUCTION}

An increasing number of snorers are seeking medical help because of attendant social and marital difficulties. It is estimated that regular snoring occurs in about $20 \%$ of adults of whom as many as $50 \%$ are over the age of 60 years. The standard surgical treatment for snoring is uvulopalatopharyngoplasty (UVPP) ${ }^{(1)}$. Patients, however, are often reluctant to undergo this procedure ${ }^{(2.3)}$ when told about the possible morbidity and unpredictable outcome. The lack of an effective, simple and relatively complication-free surgical procedure has prompted the development of a number of procedures ${ }^{(4,5,6)}$.

Palatal tightening, in which the palate is only stiffened by the use of laser without being shortened, in order to avoid palatal incompetence that may follow UVPP, was first described in 1993 by Ellis, Williams and Shneerson ${ }^{(7)}$. The use of laser (considered relatively innocuous) in palatal tightening (PT) gained popularity amongst surgeons and patients but the facility is not available in every NHS hospital. We, therefore, aimed to provide a readily-available surgical alternative, which will not only be as good as the one using laser, but also cost-effective and with little morbidity. In this preliminary report, we describe the non-laser operative technique of PT and evaluate the results in a group of 10 patients.

\section{MATERIAL AND METHODS}

Subjects A total of 18 patients, referred with the main complaint of snoring and disturbed social or marital life, were enlisted in the study between December 1996 and December 1997. Eight patients were considered unsuitable for planned surgery because four had obstructive sleep apnoea (OSA), two were heavy smokers, in one the snoring was attributed to obesity, and in one the result of snore metering was normal. Ten patients were found suitable for surgical treatment by the PT technique at the Royal Lancaster Infirmary. There were nine males and one female, with an average age of 50 (range 26 to 68 years).

Pre-operative assessment A detailed history, particularly of apnoea, was recorded. All patients were asked to complete the Epworth Sleepiness Scale form at the time of entry into the study. The scores of Epworth Sleepiness Scales ${ }^{(8)}$ are 0-7 = normal; 15 or greater $=$ high probability of some form of sleep disorder. Other parameters noted were weight gain, amount of alcohol consumption and the smoking habit. All patients with snoring were routinely referred to the department of Respiratory Medicine, for sleep and snoring investigations. The tests are designed not only to identify social snorers, but also to exclude patients with sleep apnoea. The tests range from simple overnight continuous pulse oxymetry and snore metering at home to full-scale sleep studies (polysomnometry) as an inpatient in the hospital's sleep laboratory. We consider these tests as vital preoperative assessment of these patients.

The operative procedure The operative procedure and the expected severe postoperative pain were clearly explained to all the patients. The procedure was carried out under general anaesthesia, with patients placed in the tonsillectomy position, with a Boyle Davis mouth gag in position. A central longitudinal strip of mucosa was removed from the oral surface of the soft palate, using a standard number $15 \mathrm{BP}$ blade in a long handle (Fig 1). The strip was $1.5 \mathrm{~cm}$ wide and ran from the junction of the hard and soft palate to the uvula, which was completely resected at its base (Fig 2). Adequate haemostasis was secured, using monopolar diathermy. The wound was left unsutured to heal by fibrosis.

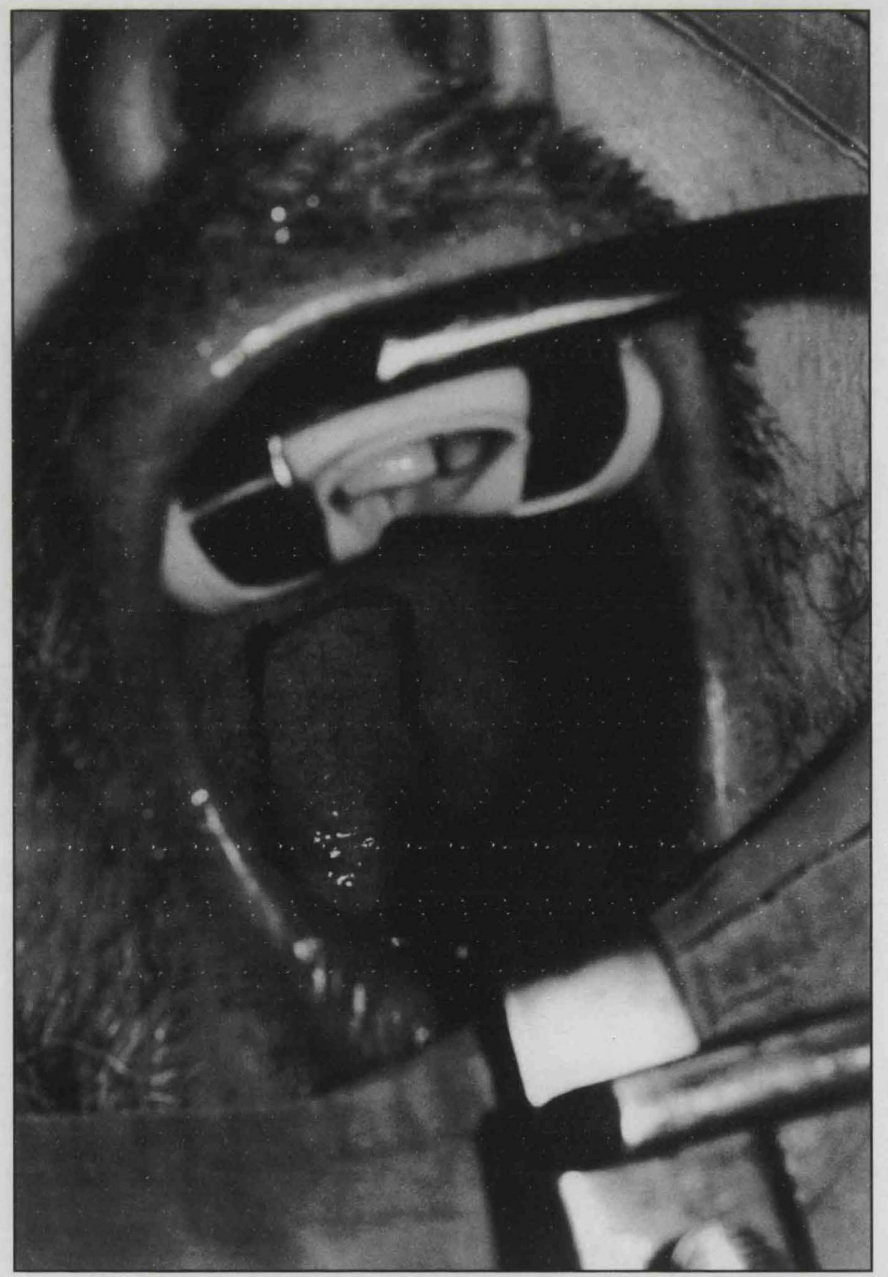

Figure 1 Central longitudinal strip marked in the palate 


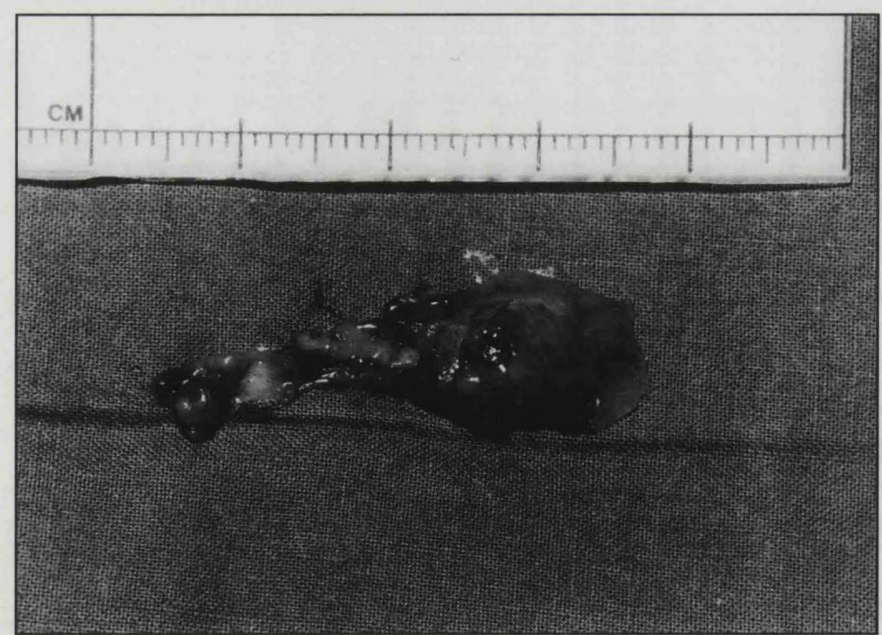

Figure 2 Resected mucosa with uvula

For the pain control, patients were given a combination of three analgesics: dispersible Voltarol Geigy (Phenylacetic acid. Diclofenac sodium) 50mg 8-hourly, slow release Zamadol Astra medica (Tramodol hydrochloride) 200mg 12 hourly and Paracetamol 1gm 6-hourly.

Postoperative discharge and follow-up All the patients were allowed home on the second day after the operation and reviewed with their partners at three, six and 12 months after the operation. They were handed a questionnaire, with four categories of painful disability viz very severe pain; moderate; mild and no pain and asked to assess the severity of pain experienced in the first 14 post-operative days. They were also asked to indicate postoperative improvement or lack of improvement of snoring on a form also containing four nominal clinical grades (Table 1) at intervals of three months for a total period of one year.

\begin{tabular}{|l|c|c|c|}
\hline Clinical Grade & $\begin{array}{c}3 \text { months } \\
\text { after }\end{array}$ & $\begin{array}{c}6 \text { months } \\
\text { after }\end{array}$ & $\begin{array}{c}12 \text { months } \\
\text { after }\end{array}$ \\
\hline Marked improvement & 8 & 9 & 9 \\
\hline Moderate improvement & 2 & 1 & 1 \\
\hline The same & 0 & 0 & 0 \\
\hline Much worse & 0 & 0 & 0 \\
\hline Total & 10 & 10 & 10 \\
\hline
\end{tabular}

Table 1 Assessment of postoperative snoring for the 10 patients

Results The soft palate healed well in all patients. No postoperative haemorrhage, infection or nasal regurgitation was reported by any of the patients. All the patients experienced severe pain in the form of sore throat and/or painful eating from the second postoperative day for about 14 days but this was adequately relieved by the combination of drugs.

The degree of the improvement in snoring, assessed by four clinical (albeit subjective) grades is shown in the table. Nine out of ten patients $(90 \%)$ reported much better results 12 months after the operation while in the tenth patient the improvement was appreciable.

\section{DISCUSSION}

The disruptive effect of snoring on social and marital life is commonly the reason for referral of patients for treatment by a specialist. It is important that adequate screening of patients is carried out to exclude conditions like obesity as a cause of snoring, and those patients who suffer from OSA. The presence of nasal obstruction must be ruled out by a thorough nasoendoscopy. The performance of appropraite sleep studies either in the form of ambulatory pulse oximetry and snore metering or full scale polysomnography is an important preoperative objective assessment in the selection of these patients. Only then must the patients be subjected to a 'curative' operative procedure.

The procedure of palatal tightening has become popular not only because of its simplicity but also because the most commonly performed procedure of UVPP may be followed by two sets of possible complications. Firstly, the palate in UVPP is shortened and this carries with it a risk of palatal incompetence causing voice change and nasal regurgitation; the procedure also limits the amount of palate that can be excised in which case the snoring may persist or become worse. Secondly, postoperative palatal oedema and haemorrhage may compromise the airway, which may need emergency intervention.

In palatal tightening, on the other hand, the soft palate heals (Figure 3 ) by slow fibrosis producing the necessary stiffening of the palate without palatal flutter or incompetence. Our results, with $90 \%$ of the patients satisfied so far, attest to the efficacy of PT which also means a bigger gain after a relatively minor procedure. We have also shown that the non-availability of the laser does not limit the success of PT as long as the principle involved in the procedure is understood. From the budgetary point of view the use of conventional surgery makes it a relatively economic exercise. There is, in fact, some evidence that the use of laser is not without appreciable post-operative morbidity ${ }^{(9)}$.

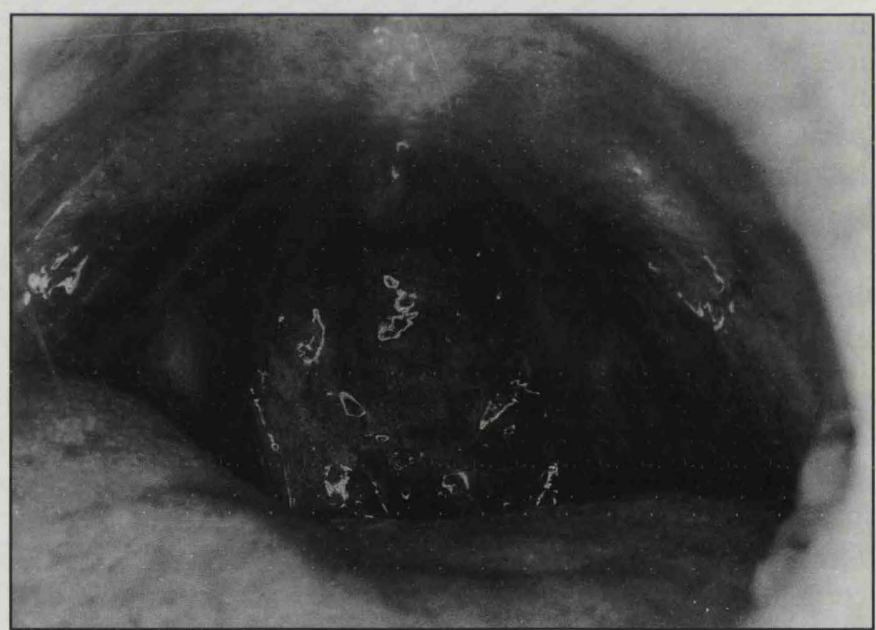

Figure 3 Postoperative healed plate

The physiological reason behind the sucess of the PT is not yet clear. Although Ellis, Williams and Shneerson ${ }^{(7)}$, using a mechanical model ${ }^{(10)}$, attributed the relief of symptoms to increased velocity of airflow seen in the Bernoulli phenomenon, we feel that the improvement in the airflow is the result of an anatomically wider nasopharyngeal isthmus produced by the absent uvula and stiffened soft palate.

\section{CONCLUSIONS}

Palatal tightening technique is a simple, safe and costeffective procedure for the successful management of social snorers. It is associated with minimal morbidity and shortterm results are encouraging. We will continue the assessment of this method and encourage others to consider this technique in the treatment of selected groups of patients. 
Acknowledgements

The authors wish to thank Professor MS Khawaja for his advice and critical comments. Special thanks to $\mathrm{Dr} R F$ Willey, Consultant Physician, and the entire team of the sleep studies laboratory at RLI for their full assessment of the patients. Our gratitude also goes to Mrs Y Dickinson for the photographs.

\section{REFENCES}

1 Fugita S, Conway W, Zorick F, Roth T Surgical correction of anatomic abnormalities in obstructive sleep apnoea syndrome; uvulopalatopharyngoplasty. Otolaryngol, Head and Neck Surg 1981;89-923-934

2 Croft CB, Goling-Wood DG Uses and complications of uvulopalatopharyngoplasty. J Laryngol and Otol 1990; 104:871-875

3 Fairbanks DNF Uvulopalatopharyngoplasty, complications and avoidance strategies. Otolaryngol, Head and Neck Surg 1990; $102: 239-245$
4 Myatt HM, Mackay IS Snoring - a simple surgical solution. Clin Otolaryngol 1996;21:419-424

5 Kamami YV The surgical treatment of snoring. J Otolaryngol 1994;23:391-394

6 Kamami YV Laser CO2 for snoring - preliminary results. Acta Oto-Rhino-Laryngol Belgica 1900;44:451-456

7 Ellis PDM, Williams JEF, Shneerson JM Surgical relief of snoring due to palatal flutter: a preliminary report. Annals Roy Coll Surg (England) 1993;75:286-290

8 Johns NW New method of assessing daytime sleepiness. Sleep 1991;14:540-545

9 Wennmo C, Olsson P Flisberg K Treatment of snoring with and without $\mathrm{CO} 2$ laser. Acta Otolaryngologica (Stockh) 1992:492:152-155

10 Huang L Acoustic control for men and machines. 1992; $\mathrm{PhD}$ thesis University of Cambridge

\section{Declaration of Geneva}

The faculty of medicine at the University of Liverpool is responsible for the education of a wide range of healthcare professionals: nurses, dentists, diagnostic and therapy radiographers, occupational therapists, orthoptists and physiotherapists as well as doctors.

It has slightly modified the Declaration of Geneva so that it is appropriate for all healthcare professions. During the faculty's graduation ceremony, the new graduates in all these professions each affirm the amended version (World Medical Association 1994 and Liverpool 1995) of the Declaration:

At the time of being admitted as a member of my profession,

I solemnly pledge myself to consecrate my life to the service of humanity:

I will give my teachers the respect and gratitude which is their due;

I will practise my profession with conscience and dignity;

The health of those in my care will be my first consideration;

I will respect the secrets that are confided in me, even after a patient has died;

I will maintain by all the means in my power the honour and the noble traditions of my profession;

My colleagues will be my sisters and brothers;

I will not permit considerations of age, disease or disability, creed, ethnic origin, gender, nationality, political affiliation, race, sexual orientation or social standing to intervene between my duty and my patient;

I will maintain the utmost respect for human life from its beginnings, even under threat, and I will not use my specialist knowledge contrary to the laws of humanity:

I make these promises solemnly, freely and upon my honour. 